Article

\title{
Reflections on the Adult Education Professoriate in Canada
}

\author{
Janet Groen * (D) and Colleen Kawalilak \\ Werklund School of Education, University of Calgary, Calgary, AB 2500, Canada; ckawalil@ucalgary.ca \\ * Correspondence: jgroen@ucalgary.ca; Tel.: +1-403-220-6440
}

Received: 21 December 2018; Accepted: 13 February 2019; Published: 22 February 2019

\begin{abstract}
Drawing on an autoethnographic approach, we offer a retrospective and current reflection on the Adult Education Professoriate within the Canadian university system. Through our autographic texts as professors within the field of adult education, as well as a review of relevant adult education literature, we consider the historical and current societal and academic trends that informed the growth and associated struggles in this academic program over the past six decades, including the launch of the Canadian Association for Studies in Adult Education. Reflecting on lessons from the past, we argue that we need to remain vigilant as professors within Canadian universities and realize that the programs we promote and offer will only thrive if we continue to survive as a valued and visible field of scholarship and practice. We further assert that our survival is contingent upon ramping up our engagement with and educating of colleagues from other disciplines, as well as work and learning contexts.
\end{abstract}

Keywords: adult education; Canada; higher education; professoriate

\section{Introduction}

For the past 30 years, the Commission of Canadian Adult Education Professors has hosted an annual meeting as part of the yearly Canadian Association for the Study of Adult Education (CASAE) Conference This meeting is quite informal and designed to create a welcoming space where we share, as colleagues, the challenges, opportunities, and changes that we are experiencing, as adult educators and academics, at our respective universities across Canada. Stories of retirements and hires, budget cutbacks, and other resource allocations, program expansions or reductions, and tensions and opportunities regarding being located within faculties of education or other faculties and departments, constitute some of what is shared, debated, and reflected upon.

This is also a space for dialogue, where we commiserate, brainstorm ideas, seek a deeper understanding, and ponder the shifts and challenges that our field of scholarship and practice will likely undergo over the next decade. While this meeting may appear, at first glance, to be less significant or productive than one designed to address a roster of more structured agenda items, we are all drawn to this gathering - one that has evolved over many years out of a thoughtful, purposeful, and mindful energy devoted to the growth and ongoing development of adult education in Canada. More specifically, when we narrow our focus to the emergence of Canadian university programs, we owe a debt of gratitude to our colleagues who had the impetus, more than half a century ago, to advocate for and build these programs and to those who initiated the creation of CASAE in 1981.

In this article, as we prepare our reflections on the Adult Education Professoriate in Canada, we acknowledge the inherent limitations. While we consider historical and current trends that have impacted adult education programs and, in turn, the role of the professoriate in Canada, we acknowledge that our own location, perspectives, and experiences inform our interpretation. In particular, as we unravel and reflect on the historical and current trends within the professoriate, 
we are informed by a vision of adult education practice and research that contributes to the "vital mission for 'really useful knowledge' that helps create a more equitable world at individual, family, community, and societal levels" [1] (p. 7). In addition, we, like Fenwick, Butterwick and Mojab [2] in their exploration of Canadian adult education research during 1990s, draw on the work of Bannjerji [3] as a caution regarding the notion of 'Canada' and "causal hidden boundaries that deny 'the other' an experience of belonging. 'Canada' then cannot be taken as a given. It is a construction, a set of presentations, embodying certain types of political and cultural communities" [2] (p. 4). Like Nesbit [4], we recognize the vastness of the Canadian landscape, rich in geographical, political, socioeconomic, and cultural diversity. Our political structure also significantly influences the role of the professoriate in adult education in Canadian universities. To elaborate, Canada is comprised of 10 provinces and territories and our universities are primarily a provincial/territorial responsibility. We also recognize that there are at least 13 different systems of governance that impact our university graduate and undergraduate adult education programs that span Canadian universities. This diverse landscape contributes to both challenges and opportunities regarding how adult education is interpreted, located, and translated regarding the development and delivery of adult education in Canada.

In this article, we begin by offering autoethnographic texts of our respective journeys from new academic hires to our current positions as professors in Adult Learning at the University of Calgary, Canada. This journey also includes taking up various formal and informal leadership roles as service, within our own university and in CASAE. Drawing from literature that is focused on the history of adult education in Canada, outside and inside the academy, we pay homage to our historical roots and to the launch of Canadian adult education academic programs, a history informed by a deep commitment to social consciousness, community action, and social justice [5]. An exploration of the growth of our academic programs over the past six decades is explored, including the launch of CASAE. We offer a discussion on current societal and academic trends and issues affecting our programs and the role of the Canadian adult education professoriate. We conclude with further reflections and dialogue on the implications for the professoriate in Canada and, more specifically, as professors in our own school of education within our Adult Learning specialization. Ultimately, our focus for this autoethnographic study is to consider the following: Against the backdrop of a rapidly changing academic context, how does the adult education professoriate in Canada maintain relevancy and continue to live out the values of community engagement and action, as well as social justice.

\section{An Autoethnographic Lens}

An autoethnographic approach informs our exploration of the adult education professoriate in Canada. This approach to our research is particularly useful in this situation as it enabled us as researchers, and as adult education professors here in Canada, to first reflect on our own experiences and in turn, situate our own narratives within the broader context-the cultural. "In autoethnography, the story is not the focus, the story is the medium. Simply put, through the power of story and sharing of experiences, stories are a pathway, a lens through which to better understand the culture of something" [6] (p. 3). We anticipate that by sharing our narratives of being adult education professors, against the backdrop of a changing university context, we will be able to engage readers, particularly those in academy as they consider their own implications of being situated in a changing context. Indeed, when we offer our stories autoethnographically, we hope to "generate stories from other" [7] (p. 310) narratives that also reveal the link between the personal and the situatedness of their experience-the cultural. As Ellis [7] (p. 37) described it, autoethnography is:

An autobiographical genre of writing and research that displays multiple layers of consciousness ... Back and forth autoethnographers gaze. First, they look through an ethnographic wide-angle lens, focusing outward on social and cultural aspects of their personal experience; then they look inward, exposing a vulnerable self that is moved by and may move through, refract, and resist cultural interpretations. 
By engaging in the process of writing about our own experiences as adult education professors, and sharing these reflections with each other, we began to appreciate the changing dynamics within our own university setting. In turn, through dialogue and a return to the literature, we were able to deepen our reflection and widen the lens to consider the implications for the adult education professoriate within Canada, whilst seeking to hold current the values of social justice and community engagement and action.

\section{Personal Narratives-Becoming Professors}

Indeed, life sometimes happens when making other plans! This sentiment resonates for both of us as we reflect on how we arrived at the doors of academia, quite unexpectedly. To put it simply, becoming university professors was not on our radar.

Prior to our arrival at the university, we had collectively accumulated approximately 50 years of experience, having worked and learned from adult learners and adult educators in a variety of diverse work and learning contexts.

Between us, we have been a social worker, staff development consultant, vocational teacher, corporate trainer, spiritual director, ESL (English as a Second Language) teacher, adult basic education instructor, family life educator, small group facilitator, parent, community volunteer, and leadership trainer. All of these roles have contributed, significantly, to our present work as associate professors in adult education and adult learning at the University of Calgary. In looking back, each experience we have gathered along the way has contributed richly to the tapestry of our learning journeys [8].

\subsection{Author One}

I arrived at the University of Calgary in 2002, as a newly hired senior instructor assigned to the Adult, Community and Higher Education Graduate Program within the Faculty of Education. At the time, student enrolment had experienced significant erosion and the Graduate Division of Education and Research, in an attempt to save adult education, decided to forge a new direction with the launch of distance learning programs in order to target a student audience located beyond Calgary and the surrounding area to include prospective students from across Canada and beyond. With little experience in distance education, my learning curve was steep. In addition to learning how to instruct and facilitate using an online learning platform, I was deeply immersed in course development for most of the courses I taught. Finally, as there was only one other colleague, soon to retire, within this specialization at this time, I assumed the role of Specialization Coordinator in my first few years of entering academia. As I look back, I acknowledge this was a harried time. In addition to working hard to develop and launch courses, I was also striving to transition from the Senior Instructor stream to a tenure-track assistant professor stream professoriate track. I was successful! While there were many challenges along the way, it was also energizing and great fun to be part of something new and exciting, where there were so many opportunities to make a contribution and to have an impact. Gradually, we were rewarded with the steady growth of students enrolled within our Master of Education program.

Much of our energy in these early years was devoted to putting our program on the Canadian map of adult education program offerings. For example, when I began to attend our annual Canadian adult education conference and introduced myself as a professor from the University of Calgary, there was often a look and commentary of surprise from adult education colleagues at other Canadian universities. Comments such as "There's still a program in Calgary! I thought it had died out!" were typical.

Fast-forward to 2019-the landscape has greatly changed. We offer a plethora of graduate programs that span Master of Education (MEd) and Doctorate of Education (EdD) cohort programs, to face-to-face Master of Arts (MA) and Philosophy of Education (PhD) programs. In addition, there are colleagues with expertise in adult education within our school of education who have established strong research agendas in our field. Further, and in collaboration with many of our graduate students, 
we maintain an active presence within our annual conference and contribute significantly to our national association, CASAE.

\subsection{Author Two}

I was in the process of completing my $\mathrm{PhD}$ when Janet arrived at the university in 2002. My doctoral research focused on transcending beyond cultural differences, in search of common ground-a search for 'oneness', as I engaged in dialogue with Indigenous Elders, adult educators, and adult learners in an Aboriginal community in Northwestern Australia. I had always been fascinated with the challenges and opportunities brought about by diversity and was particularly interested in how we came together as humankind, rather than focusing on what kept us fragmented and separate in our communities, societies, and in our world.

My field of study was in adult, community, and higher education. My work in the private, non-profit, and public sector as a social worker, family life educator, advocate for adults challenged with physical and mental disabilities, teaching and learning consultant, spiritual retreat director, and post-secondary instructor at a local college provided me a rich reservoir of life experiences from which to draw from throughout my doctoral studies. I defended my doctoral work in March 2004. Concurrent with completing my PhD studies, I applied for a tenure-track position as an assistant professor in the same specialization where I was completing my doctoral program. Shortly thereafter, I received a call from the Dean of the Faculty of Education informing me that I was the chosen candidate. I was elated and somewhat surprised-I thought I might be disadvantaged in that universities did not typically hire their own graduate students.

After accepting this academic position at my home university, I pondered how my prior. "grassroots, work experience" with adult learners who were challenged by a variety of socioeconomic and sociocultural issues would inform and support my work as a newly minted assistant professor at a university. Although I felt rather tentative about launching an academic career, I accepted the position and commenced the challenging journey of navigating the tenure-track pathway as an assistant professor on 1 July 2004. Thirteen years later, I often reflect on this career decision, one that launched me into a culture and context that felt completely foreign to me.

Within the first few years of having accepted the position, I assumed the role of Coordinator in our adult education specialization. Janet and I alternately took up this role, in support of one another and to provide service to our faculty. Although we were newly minted, non-tenured academics, it became evident that we needed to assume leadership roles early on in our careers if our specialization and program offerings were to grow and flourish. There was simply no one else to assume these roles.

\section{Connecting Our Reflections}

When we look back on our early years as assistant professors in our small specialization, we shared a common goal to develop and grow our program area. We worked closely together, engaged in frequent dialogues, developed courses, and supported one another as colleagues. We smile as we reflect back on this initial phase of our career in that our peer mentoring felt more like "the blind leading the blind". In the years that followed, our respect and fondness for one another deepened and, through dialogues that unfolded both informally and spontaneously, we grew as friends and as confidantes. We now realize that the unwavering support, wisdom, life experience, and shared commitment to co-creating community were essential and foundational to our own learning, growth, and development as budding academics. What began as informal conversations between us soon developed into more intentional and meaningful dialogue where, within a safe space, we shared our tensions, challenges, frustrations, lingering questions and ultimately used this space to engage in academic explorations and the co-writing of several articles and conference publications $[9,10]$. We sojourned the tenure-track pathway together, transitioned from assistant to associate professors and now full professors. We alternately assumed the leadership role in our area of specialization, and have taken up other leadership roles within our faculty. Specifically, Janet assumed the Graduate 
Program Coordinator role for a few years and Colleen became the Associate Dean International within our renamed faculty-the Werklund School of Education. Janet has recently joined Colleen in an Associate Dean role-specifically, Colleen has recently been reappointed to a second five-year term as Associate Dean International and Janet as Associate Dean of Graduate Programs in Education.

We acknowledge that although we have so much yet to learn, we are somewhat encouraged by how our Educational Studies in Adult Learning specialization has grown. It seems not that long ago that we were a very small group of individuals struggling to stay alive as a program area. At this time, we have established graduate programs and a healthy roster of master and doctoral students.

However, the growth of these programs comes with its own tensions. To elaborate, while our student numbers have expanded, we have had little parallel growth in the number faculty members who have expertise in adult learning. Indeed, even though at first glance, one might think we have grown dramatically in our area with nine faculty aligned with this specialization, the depth of expertise in the field of adult learning and adult education is uneven-only five of our nine colleagues have a background in this field. This, in turn, has implications for who is able and willing to take on leadership responsibilities and supervision duties within our Educational Studies area.

Regarding course offerings led by our adult learning specialization, our team launched a course development initiative five years ago, an initiative intended to address formal, informal, incidental, and lifelong learning needs and experiences of pre-service teachers. This course, entitled Professional Development and Lifelong Learning, deeply steeped in making meaning of life experiences and reflective practice, soon emerged as a core course offering in our Bachelor of Education undergraduate program. Unfortunately, due to ongoing program/curricula changes that followed over the next few years, this course has been significantly reduced in focus and duration-it is now offered as a block-type course (soon to become optional) with a narrow focus on professional development for teachers in K-12 school settings. The essence of the original course has been buried in that the content will narrowly target Teacher Professional Growth Plan(s) described as "the career-long process whereby a teacher annually develops and implements a plan to achieve professional learning objectives or goals that are consistent with the "Teaching Quality Standard" [11] (para.1).

In response to this shift, we continue to assert our voices and perspectives regarding the critical importance of addressing the lifelong learning needs of adult learners (and professionals), and extending learning beyond formal, workplace learning objectives and outcomes. Needless to say, this is an ongoing discourse that continues to beg our commitment and attention to educating our colleagues in other specializations as to the role and significance of adult learning focused coursework in pre-service teacher education programs. Serving in leadership roles in our school of education also provides additional opportunities to bring voice, focus, and some authority to discussions pertaining to these and other program offerings within our school.

In sum, as revealed by our mixed success in growing our Graduate Programs in Adult Learning and integrating adult learning within our undergraduate program, we realize that we need to remain vigilant in our focus to cultivate and, at times, protect, our sometimes fragile position within our school of education. Therefore, although neither of us aspired to assume formal leadership positions, we believe it is critical that we take up this service in support of contributing to the advancement of adult education and adult learning.

\section{Stepping Beyond the Margins}

Looking back at our evolution as an adult education program over these past 15 years, we note a gradual shift in the conversations we continue to engage in within our own school of education and beyond. Driven by a desire to articulate a thoughtful, purposeful, and strategic mission and vision as an adult education specialization located within our school, we focused intentionally on integrating critical inquiry, human rights, and social justice, and on validating other ways of knowing and being in the world. We also sought to explore, more deeply, the meaning of lifelong learning and we addressed this by focusing on informal, incidental, and tacit learning in our teaching practice and in our research 
and service. Being intentional in this way mostly shifted our focus from "merely surviving" as an adult education specialization to a more intentional stance in support of "thriving" in our field of scholarship and practice. We continue to take these steps intentionally but cautiously. Our caution is in response to the dissolution and erosion of adult education programs occurring in Canada, in the United States, in the UK and Australia, and in Europe. We believe that, by setting our sights beyond surviving as a field of scholarship and practice, we need to be strategic in how and where we develop and offer our adult education programs and initiatives. This means stepping beyond environments and program areas that have typically focused on adult education and adult learning, into spaces and places that are less familiar and sometimes uncomfortable. To state this from another perspective, we argue that, as adult educators, we need to be advocates and educate our valued colleagues, from other disciplines and professional practice contexts, on the significance of adult education and adult learning, as well the associated values, within their respective foci, fields, and disciplines. In our own day-to-day work at our university, we continue to navigate this tension as we hold on to the essence and roots of adult education, whilst moving into more mainstream pre-service teacher education. This discomfort refers to a shift in focus in pre-service teacher education to include illuminating "teachers as lifelong, adult learners". This shift is important as, prior to the development and offering of Professional Development and Lifelong Learning, this program focused on teaching and facilitating learning within child-centered, K-12, learning environments. Providing a course that focused on the learner within all of us and on being fascinated as teachers and as lifelong, adult learners, adds significantly to our pre-service teacher education program.

\section{Re-Tracing Our Adult Education Roots and History}

As we now turn to the literature, to situate our autoethnographic reflections within the broader Canadian context, we draw primarily on journal articles, books, and conference proceedings, from the field of adult learning and adult education. Key literature streams included the following: autoethnography, reflective practice, adult education practice in higher education contexts, adult education history, and research trends in adult education. Additionally, the majority of our references are from Canadian publications, as we found a paucity of research on the Canadian context of adult education beyond our own borders.

The deep roots and rich history of adult education in Canada significantly predates the spawning of adult education, university programs in Canada in the 1950s, a launch that aligned to the evolution of similar programs being developed in the United States. These roots and history include the adult education and literacy movement, community development and social action initiatives, the development of apprenticeship and vocational education, and the emergence of Farmers' and Women's Institutes, to name only a few. This heritage of consciousness and social action existed long before the actual formalization of adult education in universities in the late 1940s and early 1950s.

It was at this time when Roby Kidd and Alan Thomas, two of our first Canadian adult education professors, joined their colleagues in the United States at one of the initial meetings of the American Commission of Professors [12]. At this meeting, the possibility of creating a discipline of adult education was explored. While the underlying philosophical approach emerging out of these early meetings had a profound impact on the development of North American adult education programs, Canadian programs adopted the associated beliefs and values, albeit, with some concern:

American thinking about how adult education ought to be studied profoundly influenced Canadian thinking in its professionalization phase. For one thing, the individualism of American thinking rested uneasily with Canadian collective orientations to the world ... Canadian adult educators had not repressed their own critical traditions [12] (p. 4).

During the 1960 and 1970s, Canadian universities experienced rapid growth in adult education programs and, like our counterparts in the United States, adult educators worked hard to implement the vision from the 1950s to create a discipline that would be viewed and regarded as credible, within the broader university community: 
During this quarter century both Canadian and US academic adult educators were focused on building enterprise cohesiveness and unity among diverse parts of the field. They worked against field fragmentation and the historical marginalization of the adult education in sociocultural institutions. [13] (p. 143)

In an article that reviewed Canadian adult education research trends over the past several decades [14], we spoke to this push for academic credibility and to how this emphasis significantly impacted our own research agendas. We also explored the early influences of positivistic research methodologies and psychological and individualistic frameworks that addressed and informed practical and the more applied needs of the adult education field in areas such as: program planning, administration, instructional materials and methods, and adult learning. After the heady growth of programs during the 1960s, 1970s, and in the early 1980s, the potential opened up for a new era, a time when professors in Canadian adult education programs aimed to forge their own identity and agenda, a distinct agenda separate from our neighbors to the south. In many ways, the desire to create our own identity was really an aspiration of reclamation, the reclamation of our historical roots with a transparent focus on social justice, community development, and developing a critical consciousness. Two Canadian adult education institutions, the Canadian Association for the Study of Adult Education (CASAE) and the Canadian Journal for the Study of Adult Education (CJSAE), were created during this time. Both remain with us today.

Tracking the beginnings of CASAE, Boshier [15] noted that doctoral student, Judith Mastai from the University of British Columbia, extended an invitation to every professor listed in the Directory of Professors of Adult Education in Canada [16] (Bosher and Thiesfeld, 1978) to attend a meeting to discuss the formation of a Canadian organization. Motivated by the intention to chart our own destiny and to take up our own issues as Canadian adult educators, CASAE emerged as a national association on 6 May 1980:

Let us be practical. We cannot expect our neighbors, however hospitable, to always understand why Canadians think something is important, or regrettable, or desirable—and [why] such values guide the selection of questions for further study ... We must expect to speak among ourselves about our own experience. (CASAE, 1981b, as cited by [15], p. 23).

The implications of this decision would play a central role in charting our own destiny as professors and in the development of adult education programs in Canadian universities. With the launch of CASAE, we were able to hold our own annual conference, as an academic association, under the auspices of the larger Canadian Federation for the Humanities and Social Sciences Research Conference and created our own journal titled The Canadian Journal for the Study of Adult Education (CJSAE). Navigating the waters through the 1980s and 1990s presented many challenges in that we experienced the push and pull of larger societal and institutional forces within and beyond our Canadian borders. Welton [12] (p. 3) spoke to the PhD program in adult education at the Ontario Institute for Studies in Education (OISE) being revoked in the 1980s "on the grounds that professional publications were not academically respected" and to adult education programs at the University of British Columbia and the University of Montreal who were also feeling threatened; concerned that they would lose their voice due to being located within Faculties of Education. By the 1990s, adult education was still on unstable ground in Canadian universities. Welton [12] (p. 5) referred back to July 1995 when:

Michael Collins and his associates at the University of Saskatchewan called a major emergency conference in Canmore, Alberta, to examine the question of the future of adult education as a field of study and practice. Prominent scholars came from Britain, Australia, New Zealand, the United States, and Canada. The mood was even more morose than 10 years earlier.

Some the tensions felt by Canadian adult education professors during the 1980s and 1990s can be linked back to the earlier vision of adult education cast in the 1950s; this vision promoted 
an andragogical and instrumental framework of learning and research. Many of our colleagues believed we were drifting off course from our earlier grassroots heritage. Indeed, in a similar vein to much of the adult education research that came out of the 1970s, Kjell Rubenson [17] (para. 7) (2000), in his seminal article that mapped North America research trends in our field during the 1980s, indicated that there remained "a strong emphasis on psychologically oriented theories in North America and, in relative terms, a greater preoccupation with social theory in Europe" (para. 17). Rubenson [17] also inferred that little research drew from a critical paradigmatic orientation and, consequently, there was little to distinguish Canadian adult education research from larger North American trends. Fenwick, Butterwick, and Mojab [2], in their analysis of the "liberatory potential" (p. 15) of Canadian adult education research trends in the 1990s, generally concurred with Rubenson's concerns. They did, however, extend a glimmer of hope. After their review of CASAE conference proceedings, graduate student theses, and the CJSAE, Fenwick, Butterwick, and Mojab [2] (p. 14) found that "social movements, civil society and community were contexts of concern during this decade but they remained on the margins as did discussions about class, race, and sexuality". A pedagogical focus with planning, instruction and evaluation maintained a strong research presence during this period of time. Concern with the over-riding emphasis on a fairly instrumental approach to our adult education teaching and research programs in Canada became increasingly urgent when placed beside significant societal changes. Specifically, the late 1970s spelled the demise of socialist aspirations of the left and the beginning of neoliberal, economic policies. Neoliberal policies were becoming deeply entrenched and, more specifically, adult learning and education were being taken up as a pathway to unemployment reduction and in support of increased productivity within business and industry contexts [18].

Indeed, over this past decade, a rich discourse on whether adult education programs in Canadian universities have succumbed to a professionalized entity, located placidly within the existing societal structures, continues to be debated and explored within our community of Canadian adult educator professors [19-21].

\section{Current Trends and Issues}

Gordon Selman and his son Mark Selman authored an article entitled The Life and Death of the Canadian Adult Education Movement [19] response to a series of conversations between Gordon Selman and Alan Thomas, one of the key adult education professors introduced earlier in this article. Alan Thomas played a central role in shaping the initial Canadian university programs in adult education. When Selman and Thomas commenced their academic careers in the 1950s, they believed that they were participating in something new and exciting. They hoped that the earlier social justice leanings in the practice of adult education would become the impetus and driving force for the development of adult education university programs. Selman and Selman [19] (2009) wrote that, "leaders in the field continued to share the conviction that adult education had a vital role to play in both the personal and professional lives of adults" (p. 19). However, over the duration of his long career, Selman senior felt that we had lost our way in that we had gradually shifted our focus and aspirations to become more professionalized and institutionalized. While we, as professors, put our energy into developing undergraduate and graduate programs in adult education, alongside launching our research agendas, Selman and Selman [19] (2009) felt that grassroots, adult education had become a lesser priority. In addition, they pointed out that the term lifelong learning, learning once understood as available and accessible to everyone through day-to-day lived experience, was now being appropriated by government to foster economic growth. Ultimately, as we gained stature within our post-secondary institutions, corporate settings, and in government agendas, we retreated from collective action. "The actual practice of adult education as a means to address the interests of people facing disadvantages, or aimed at the public good is [no longer being] well supported and is sometimes actively discouraged" [19] (p. 23). 
Tom Nesbit and Budd Hall [20], during a conference presentation at the Adult Education Research Conference held in the United States, strongly refuted the arguments proffered by Mark and Gordon Selman. To elaborate, Nesbit and Hall [20] (p. 490) offered compelling evidence that the field of adult education and learning was alive and well in Canada, that there are Canadian adult education programs that align to social movements and research, and that adult educators/professors remain actively engaged in support of this agenda:

Canadian adult educators have been instrumental in establishing centers that carry out research on social movements - such as the Coady International Institute in Antigonish, the Transformative Learning Centre and the Centre for the Study of Education and Work in Toronto-and we play a part in many others.

Nesbit and Hall also pointed to the emergence of Indigenous adult education led by Indigenous scholars. Citing this as an exciting, new development, Nesbit and Hall highlighted the recent appointment of five Indigenous, Assistant Professors within our own school of education at the University of Calgary; one of these Indigenous scholars was recently appointed to our own Educational Studies in Adult Learning specialization. Nesbit [22] (2011) argued that we are not hiding in our own ivory towers, rather "there is evidence to suggest that the opposite is true: levels of social action and interest are increasing ... Canadian adult education remains as involved in such collective action as it has been throughout its history" (p. 4). Additionally, our research agendas have gradually and irrefutably taken up the concerns of social inequity and injustices in local, national, and global contexts. In Donovan Plumb's [18] overview of the more recent research agendas of Canadian adult education professors, he noted the following trends: research on heteronormative biases in Canadian adult education theory and practice; an exploration of ways that adult education can contribute to deepening capacities for spirituality; an examination of how globalization is destroying indigenous cultures and the environment that sustains all of us; a focus on unions as a key space for adult learning; and finally, pulling the curtain back on the dramatic inequities of human rights, poverty, and violence triggered by contemporary capitalism. We [14] (p. 36) (Groen and Kawalilak, 2013) also noted a similar research foci contributing to "the 'liberatory' tradition of adult education: citizenship, gender, health, adult literacy, immigration, transmigration, transformative learning, diversity, race, consumerism, and adult learning communities in varied contexts".

\section{In Summary}

As we situate our autoethnographic accounts against the backdrop of the historical overview and current realities of Canadian adult education programs, we concur with Nesbit and Hall's [20] (p. 494) position that these programs, the Canadian adult education programs and the Canadian adult education professoriate, still remain committed to contributing, in multiple and vibrant ways, to "Canada's long-term education and societal development ... and still following in the noble of adult education tradition". We argue, however, that we need to remain vigilant that, as professors within Canadian universities and as a community of scholars and practitioners, the programs we promote and offer will only thrive if we continue to survive, within our respective universities, as a valued and visible field of scholarship and practice. We further assert that our survival is contingent upon ramping up our engagement with and educating of colleagues from other disciplines and work and learning contexts. We refer to focusing more attention on the significance and relevance of locating the historical roots of adult education-social justice, equity, human rights, and collective community action-within contemporary, adult, work and learning contexts.

Although many are located within faculties or schools of education in our respective universities, some of our colleagues reside outside of 'Education' in other university faculties that focus on policy development, higher education, community and international development, communication and culture, social work, continuing education and lifelong learning, and women's studies. The debate regarding opportunities, tensions, and challenges, pertaining to where we are located and to how this 
affects and influences our teaching, research, and service, continues. We suspect that this discourse will be ongoing as adult education and adult learning is not context-specific and will never and should not be confined and limited to a particular discipline. We continue to resist confining adult education to any one, particular area as, if we take this approach, we will limit the important work and learning that has the potential to resonate with, influence, and impact the lifelong learning journeys of adult learners who span multiple and diverse work and learning contexts.

Author Contributions: Writing original draft, J.G. and C.K., writing, review\& editing, J.G. and C.K., Corresponding, J.G.

Funding: This paper received no external funding.

Conflicts of Interest: The authors declare no conflict of interest.

\section{References}

1. Nesbit, T. Introduction. In Contexts of Adult Education: Canadian Perspectives; Fenwick, T., Nesbitt, T., Spencer, B., Eds.; Thompson Press: Toronto, ON, Canada, 2006; pp. 13-22.

2. Butterwick, S.; Fenwick, T.; Mojab, S. Canadian adult education trends in the 1990s: Tracing liberatory trends. Can. J. Study Adult Educ. 2011, 2, 1-19.

3. Bannerji, H. Geography lessons: On being an insider/outsider to the Canadian nation. In Dangerous Territories: Struggles for Difference and Equality in Education; Roman, L., Eyre, L., Eds.; Routledge: New York, NY, USA, 1997; pp. 23-42.

4. Nesbit, T. Canadian adult education: A critical tradition. In Building on Critical Traditions: Adult Education and Learning in CANADA; Nesbit, T., Brigham, S., Gibb, T., Taber, N., Eds.; Thompson Press: Toronto, ON, Canada, 2013; pp. 1-18.

5. Welton, M. A bird's eye view of Canadian adult education history. In Building on Critical Traditions: Adult Education and Learning in Canada; Nesbit, T., Brigham, S., Gibb, T., Taber, N., Eds.; Thompson Press: Toronto, ON, Canada, 2013; pp. 19-28.

6. Kawalilak, C.; Groen, J. Restorying the present by revisiting the past: Unexpected moments of discovery and illumination through museum learning. J. Adult Contin. Educ. 2016, 22, 152-167. [CrossRef]

7. Ellis, C. Ethnographic I; Altamira Press: Walnut Creek, CA, USA, 2004.

8. Groen, J.; Kawalilak, C. Pathways to Adult Learning: Professional and Education Narratives; Canadian Scholars Press: Toronto, ON, Canada, 2014.

9. Kawalilak, C.; Groen, J. A dialogue about dialogue-Reflections of two adult educators. In Proceedings of the 36th National Conference of the Canadian Association for the Study of Adult Education, Toronto, ON, Canada, 28 August 2017.

10. Groen, J.; Kawalilak, J. Creating space for transformative learning in the workplace. New Dir. Adult Cont. Educ. 2016, 152, 61-72. [CrossRef]

11. Alberta Gov't. Alberta Education Teaching Quality Standard; Ministry of Education: Edmonton, AB, Canada, 2017. Available online: https://education.alberta.ca/media/3739620/standardsdoc-tqs-_fa-web-2018-0117.pdf (accessed on 21 February 2019).

12. Welton, M. Falling into the company of adult educators: Travels with CASAE. Can. J. Study Adult Educ. 2011, $23,1-10$.

13. Grace, A. Canadian and US adult learning (1945-1970) and the cultural politics and place of lifelong learning. Int. J. Lifelong Educ. 2000, 19, 141-158.

14. Groen, J.; Kawalilak, C. The tapestry of adult education research in Canada. In Building on Critical Traditions: Adult Education and Learning in Canada; Nesbit, T., Brigham, S., Gibb, T., Taber, N., Eds.; Thompson Press: Toronto, ON, Canada, 2013; pp. 29-38.

15. Boshier, R. True north strong and free: Three wise men and the founding of CASAE/ACEEA. Can. J. Study Adult Educ. 2011, 23, 11-25.

16. Bosher, R.; Thiesfeld, B. Canadian Professors of Adult Education: A Directory; Department of Adult Education, University of British Columbia: Vancouver, BC, Canada, 1978. 
17. Rubenson, K. Revisiting the Map of the Territory. In Proceedings of the Adult Education Research Conference Proceedings, Vancouver, BC, Canada, 2-4 June 2000; Available online: https:/ / newprairiepress.org/aerc/ 2000/papers/78/ (accessed on 21 February 2019).

18. Plumb, D. Critical adult education in Canada in the time of CASAE. New Dir. Adult Contin. Educ. 2009, 124, 5-15. [CrossRef]

19. Selman, G.; Selman, M. The life and death of the Canadian adult education movement. Can. J. Univ. Contin. Educ. 2009, 35, 13-28. [CrossRef]

20. Nesbit, T.; Hall, B. Canadian adult education: Still moving. In Adult Education Research Conference Proceedings; California State University: Sacramento, CA, USA, 2011.

21. Selman, M. Canadian adult education: Still a movement. Can. J. Univ. Continu. Educ. 2011, 37, 1-7. [CrossRef]

22. Nesbit, T. Canadian adult education: Still a movement. Can. J. Univ. Continu. Educ. 2011, 37, 1-13. [CrossRef]

(C) 2019 by the authors. Licensee MDPI, Basel, Switzerland. This article is an open access article distributed under the terms and conditions of the Creative Commons Attribution (CC BY) license (http://creativecommons.org/licenses/by/4.0/). 